\title{
Fibrogenesis in alcoholic chronic pancreatitis: the role of tissue necrosis, macrophages, myofibroblasts and cytokines
}

\author{
Sönke Detlefsen, Bence Sipos, Bernd Feyerabend and Günter Klöppel \\ Department of Pathology, University of Kiel, Kiel, Germany
}

\begin{abstract}
Myofibroblasts and cytokines such as transforming growth factor- $\beta 1$ (TGF- $\beta 1$ ) and platelet-derived growth factor (PDGF)-B have been found to play an important role in pancreatitis-associated fibrogenesis. It is still unclear, however, where in the inflamed pancreas and when these fibrogenic cells and cytokines can be detected. In this study we examined pancreatic tissue from patients with alcoholic chronic pancreatitis to determine the localization and distribution of myofibroblasts and the expression of cytokines in relation to the tissue damage and the activity of the inflammatory process. In tissue from pancreatic specimens from 59 patients with alcoholic chronic pancreatitis the inflammatory process was histologically staged. Myofibroblasts and the cytokines latency-associated peptide, a TGF- $\beta$ propeptide, TGF- $\beta$ receptor II, PDGF-B and the $\alpha$-isoform of the PDGF receptor were immunohistochemically identified in 10 selected cases representing the four defined stages of alcoholic chronic pancreatitis. In stage I, the stage with overt tissue injury, myofibroblasts were numerous and especially associated with macrophages around areas of necrosis. In stage II, the stage with cellular fibrosis, myofibroblasts were the main component of the interlobular tissue. In stage III, the stage with dense fibrosis, myofibroblasts were rare, and in stage IV, when calculi were present, myofibroblasts were only detected adjacent to duct ulcerations caused by calculi. Latency-associated peptide and TGF- $\beta$ receptor II as well as PDGF-B and PDGF receptor- $\alpha$ were mainly expressed by macrophages, myofibroblasts and epithelial cells in stages I and II. The results suggest that the fibrogenic process in alcoholic chronic pancreatitis is initiated by a cytokine-based interplay of macrophages and myofibroblasts that follows tissue injury.

Modern Pathology (2006) 19, 1019-1026. doi:10.1038/modpathol.3800613; published online 5 May 2006
\end{abstract}

Keywords: pancreatic fibrosis; alcoholic chronic pancreatitis; fibrogenesis; myofibroblast; macrophage; cytokines

Most chronic diseases of the exocrine pancreas are associated with the development of fibrosis (for a review see Klöppel et $a l^{1}$ ). This is particularly the case in chronic pancreatitis. Recently, the basic mechanisms underlying fibrogenesis in the pancreas were revealed. Like in the liver, ${ }^{2}$ connective tissue production and synthesis has been ascribed to stellate-shaped cells, that is, the pancreatic stellate cells, which when activated by cytokines are transformed into myofibroblasts. ${ }^{3}$ The activated pancreatic stellate cells, or myofibroblasts, were found to express smooth-muscle actin and desmin, while the inactivated pancreatic stellate cells were characterized by their capacity to store lipids and vitamin $\mathrm{A}^{3,4}$ In in vitro studies it was shown that pancreatic stellate cells are transformed into

Correspondence: Dr G Klöppel, MD, Department of Pathology, University of Kiel, Michaelisstrasse 11, 24105 Kiel, Germany. E-mail: gkloeppel@path.uni-kiel.de

Received 21 December 2005; revised 23 March 2006; accepted 31 March 2006; published online 5 May 2006 proliferating myofibroblasts mainly by transforming growth factor- $\beta$ (TGF- $\beta$ ), platelet-derived growth factor (PDGF) and fibroblast growth factor- $\beta$ $\left(\right.$ FGF- $\beta$ ) ${ }^{5-7}$ Immunohistochemical studies localized TGF- $\beta$ (as well as its active components and receptor TGF- $\beta$-R) and PDGF to inflammatory cells and to epithelial cells in chronically inflamed tissue in the pancreas. ${ }^{5,8-10}$ Further, myofibroblasts have been described in the normal human pancreas. ${ }^{11,12}$ While these studies identified the key players in pancreatic fibrosis, so far little is known about the 'natural history' of fibrogenesis in the course of chronic pancreatitis. It is unclear what initiates this process and maintains it and how the various cellular compartments, the inflammatory, the stromal and the epithelial cells, are involved. Here, we pursue these questions with regard to the development and course of fibrosis in alcoholic chronic pancreatitis, the most common type of chronic pancreatitis in westernized countries. ${ }^{13-15}$

Based on the necrosis-fibrosis sequence as underlying pathogenesis of alcoholic chronic pancreatitis, ${ }^{16}$ 
the hypothesis is proposed that the initial lesion in alcoholic chronic pancreatitis, the autodigestive tissue necrosis, causes by its resolution the induction of a fibrotic reaction. We therefore studied the occurrence and distribution of the main cellular components of this fibroinflammatory process, macrophages and myofibroblasts (ie activated pancreatic stellate cells). We also examined the immunohistochemical expression pattern of two cytokines and their receptors involved in fibrogenesis, that is, the latency associated peptide (LAP), a propeptide of TGF- $\beta$, and the respective receptor TGF- $\beta$ RII, and PDGF-B and the respective receptor PDGF-R $\alpha$. Finally, in an attempt to relate the findings to the dynamics of the disease, we defined four histological stages of alcoholic chronic pancreatitis that are thought to characterize its early and late phases.

\section{Materials and methods}

\section{Tissue}

Paraffin-embedded formalin-fixed tissue blocks were obtained from surgical specimens of 44 men and 15 women with alcoholic chronic pancreatitis (according to the criteria previously defined by Ammann et $a l^{13}$ ), mean age 48 years, age range 31 66 , who had undergone partial pancreatic resection (42 Whipple resections, 17 left-sided pancreatic resections) because of pseudocysts, jaundice and/ or pain. From each case there were at least two and in some cases 10 tissue blocks available, in average five tissue blocks were examined. All sections were stained with haematoxylin and eosin and periodic acid-Schiff. Snap frozen tissue was additionally available in 10 cases.

\section{Histological Staging of Alcoholic Chronic Pancreatitis}

In order to be able to relate the development of the fibrosis in alcoholic chronic pancreatitis to the course of this disease, ${ }^{16}$ we classified the pancreatic changes that we observed in the specimens according to the presence and abundance of necrotic, inflammatory and fibrotic alterations. Four histological stages were distinguished and defined as follows (Table 1).

In stage I (Figure 1a), the pancreatic tissue showed necrotic changes as well as cellular perilobular fibrosis. We regarded small areas of fatty tissue necrosis, large areas of haemorrhagic necrosis and/ or pseudocysts as necrotic foci. ${ }^{17}$ The margins of the necrotic foci were lined by numerous macrophages, some transformed into foamy cells. In addition there were lymphocytes, plasma cells and granulocytes, although fewer in number. The inflammatory infiltrate was intermingled with fibroblasts, which were the main component of the cellular fibrotic tissue filling the peri- and interlobular spaces in the vicinity of the necrotic areas. Acinar cell or duct
Table 1 Staging of alcoholic chronic pancreatitis ${ }^{\mathrm{a}}$

Stage Main features

I Mild and focal cellular interlobular fibrosis involving single groups of lobuli and adjacent to areas with necrosis (ie, fat necrosis and/or pseudocyst). No duct alterations.

II Intensive cellular interlobular fibrosis involving many lobuli. No duct alterations.

III Marked dense interlobular fibrosis and focal intralobular fibrosis involving many lobuli. Duct distortion and dilatation. Protein plugs.

IV Extensive dense interlobular and intralobular fibrosis involving most lobuli. Duct distortion and massive duct dilatation. Calculi.

${ }^{\mathrm{a}}$ For details see text.

necrosis was rare and only observed in areas with extensive interstitial fat and/or haemorrhagic necrosis.

In stage II (Figure 1b), there was intensive cellular interlobular fibrosis that, in addition to fibroblasts, contained scattered macrophages, lymphocytes and occasionally granulocytes. The inflammatory infiltrate occasionally also involved acinar tissue. The interlobular ducts were embedded in the cellular fibrosis, but appeared to be unaltered.

In stage III (Figure 1c), the pancreatic tissue showed marked interlobular fibrosis associated with intralobular fibrosis that involved single lobuli or groups of lobuli and replaced acinar cells. The fibrotic tissue contained a few fibroblasts, but myofibroblasts were rare. Further, only scattered macrophages, lymphocytes and plasma cells were detected, while granulocytes were absent. Many of the interlobular ducts embedded in fibrotic tissue showed an irregular lumen and contained protein plugs.

In stage IV (Figure 1d), the extent of the inter- and especially intralobular fibrosis was greater than in stage III. In addition, many of the interlobular ducts, which were severely distorted and showed irregular lumina, contained calculi. In some ducts the calculi had eroded the epithelium. The destruction of the epithelium was accompanied by an inflammatory infiltrate in the adjacent area consisting of granulocytes, macrophages, some lymphocytes and plasma cells and also fibroblasts.

\section{Immunohistochemistry}

Out of the 59 cases of alcoholic chronic pancreatitis that were staged according to the above protocol 10 cases (three each showing stages I and II, and two each showing stages III and IV) were selected for immunohistochemical examination with antisera against $\alpha$-SMA, desmin, LAP, TGF- $\beta$-RII, PDGF-B and PDGF-R $\alpha$. From the 10 cases both formalin-fixed and snap frozen tissue was available. Table 2 lists the various antisera used in this study.

Immunohistochemical analysis was carried out on serial sections using the avidin-biotin-peroxidase 

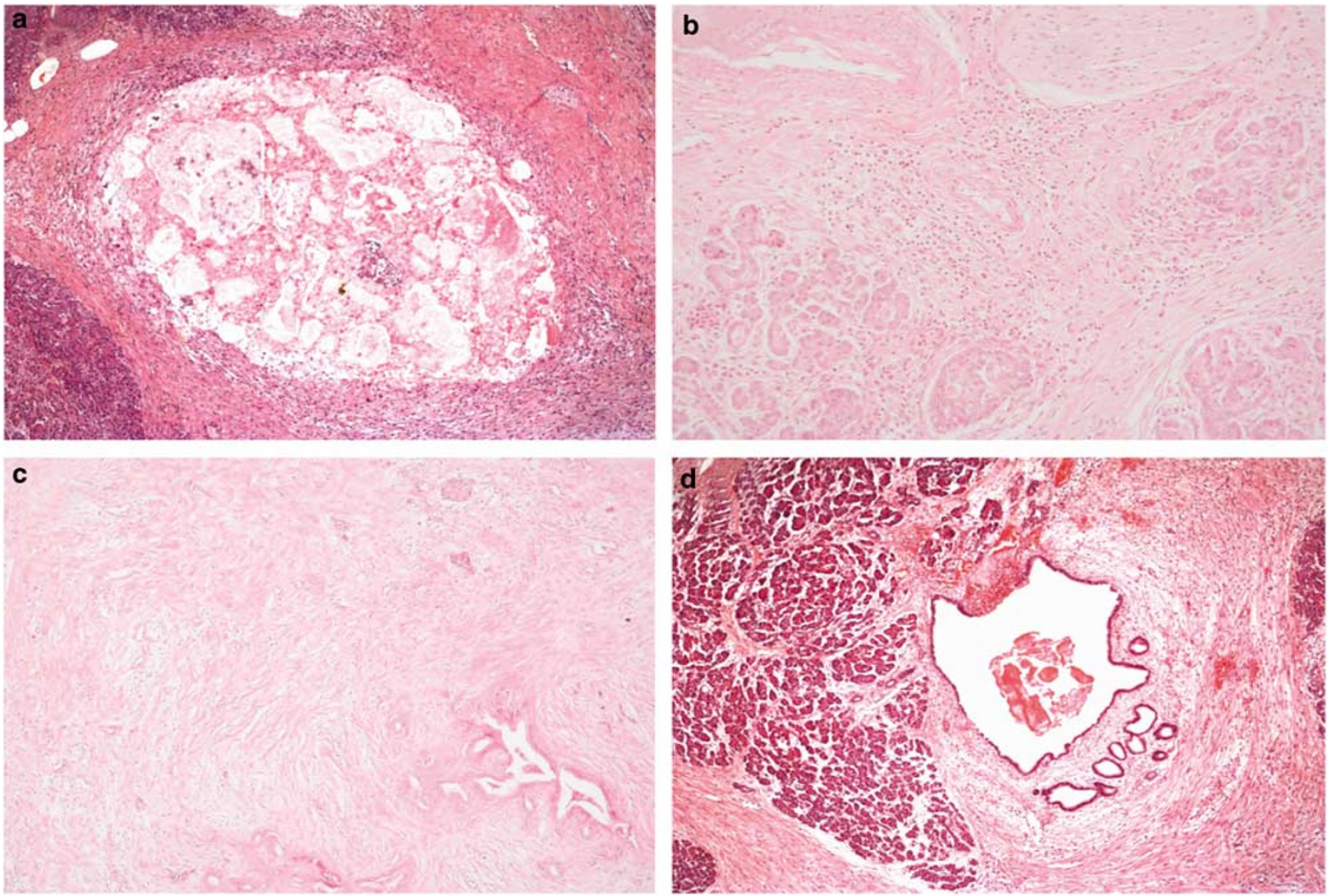

Figure 1 Four histological stages of alcoholic chronic pancreatitis. (a) Stage I: wall of a pseudocyst showing an outer layer composed of connective tissue and an inner layer consisting of granulation tissue surrounding central fat tissue necrosis (H\&E, $\times 50)$. (b) Stage II: interlobular inflammatory infiltrate consisting mainly of macrophages, myofibroblasts and some lymphocytes (H\&E, $\times 100)$. (c) Stage III: marked interlobular and intralobular fibrosis surrounding an unaffected islet and pancreatic ducts with irregular lumina (H\&E, $\times 50)$. (d) Stage IV: interlobular duct containing a calculus that has focally eroded the epithelium, causing ulceration and an inflammatory reaction in the adjacent area $(\mathrm{H} \& \mathrm{E}, \times 50)$.

Table 2 Antibodies used for immunostaining

\begin{tabular}{llll}
\hline Antigen/antibody & Host sp. & Source & Working dilution \\
\hline$\alpha$-SMA & Mouse & DAKO (Glostrup, Denmark) & $1: 20$ \\
Desmin & Rabbit & DAKO (Glostrup, Denmark) & $1: 20^{\mathrm{a}}$ \\
CD-68 & Mouse & DAKO (Glostrup, Denmark) & $1: 100$ \\
LAP & Goat & R\&D-Systems (Wiesbaden, Germany) & $1: 20$ \\
TGF- $\beta$-RII & Rabbit & Upstate Biotechnology (New York, USA) & $1: 20^{\mathrm{a}}$ \\
PDGF-B & Rabbit & Calbiochem (Merck Biosciences, Darmstadt, Germany) & $1: 10$ \\
PDGF-R $\alpha$ & Rabbit & Santa Cruz Biotechnology (California, USA) & $1: 400^{\mathrm{a}}$
\end{tabular}

${ }^{\mathrm{a}}$ Antigen retrieval with boiling.

technique (ABC ELITE, Vector Laboratories, Burlingame, CA, USA). Endogenous peroxidase activity was blocked with $0.3 \% \mathrm{H}_{2} \mathrm{O}_{2}$ solution for $20 \mathrm{~min}$ before the staining. The slides were either directly immunostained or first pretreated by incubation with protease or boiling in citrate-buffered saline for $3.5 \mathrm{~min}$. For the PDGF-B staining we used tissues snap frozen in isopentane cooled with dry ice, and stored at $-80^{\circ} \mathrm{C}$ until cryostat sectioning for immunohistochemistry.

\section{Immunohistochemical Analysis and Scoring}

Cells located in inflammatory fibrotic tissue and displaying $\alpha$-SMA expression were identified as myofibroblasts. In addition to myofibroblasts, cells expressing the antigens CD68, LAP, TGF- $\beta$-RII, PDGF-B and PDGF-R $\alpha$ were examined. The frequency and location of the labelled cells were evaluated and semiquantitatively scored. The following locations were analysed: in stage I, the 
analysis focused on the areas around tissue necrosis and adjacent interlobular areas; in stage II, on the areas with cellular interlobular fibrosis; in stage III on areas with dense interlobular fibrosis, and in stage IV on areas showing interlobular fibrosis with or without duct ulcerations caused by calculi. In each case, at least two of the above-mentioned areas were examined by counting approximately 200 cells per area of the respective cell population, including myofibroblasts, macrophages, ductal cells, acinar cells, lymphocytes and granulocytes. The immunoreactivity was scored as 0 if less than $2 \%$ of a given cell population were stained, as 1 if $2-10 \%$ were stained, as 2 if 10 to $50 \%$ were stained, and as 3 if more than $50 \%$ were stained.

\section{Results}

Evaluation of the 59 specimens with alcoholic chronic pancreatitis revealed that seven of the cases could be ascribed to stage I, 22 to stage II, 17 to stage III and 13 to stage IV. Stage I cases usually also contained minor areas displaying stage II and/or stage III, and stage II cases also had some areas representing the characteristics of stage III or even stage IV. The minor areas that showed stages of alcoholic chronic pancreatitis different from the dominant stage accounted for less than $20-30 \%$ of the total section area evaluated.

\section{Myofibroblasts}

In stage I, myofibroblasts, identified by their triangular, stellate-shaped morphology combined with $\alpha$-SMA expression, were frequent around foci of tissue necrosis (Figure 2a). Here, they were found in close association with macrophages (Figure 2b). Only a small fraction (approximately $30 \%$ ) of $\alpha$-SMA positive myofibroblasts were also desmin positive. Most myofibroblasts were found to express PDGF-R $\alpha$ (Figure 2c, Table 3) and TGF- $\beta$-RII. LAP was expressed only in a few myofibroblasts and PDGF$\mathrm{B}$ was lacking.

In stage II, myofibroblasts were most frequent in the interlobular areas, where they were arranged in a herringbone pattern (Figure 3a). Most of them were positive for PDGF-R $\alpha$ and TGF- $\beta$-RII (Figure $3 \mathrm{~b}$, Table 3), a few stained for LAP, but lacked PDGF-B. Again, myofibroblasts were found in close association with macrophages (Figure 3c).

In stage III, only few myofibroblasts were identified in the interlobular areas (Figure 4). Their PDGF$\mathrm{R} \alpha$ and TGF- $\beta$-RII immunoreactivity and their expression of $\alpha$-SMA and desmin appeared to be less intense than during the first two stages.

In stage IV, myofibroblasts were found adjacent to the destruction of ductal epithelium by calculi, admixed with an inflammatory infiltrate (Figure 5). Most of these myofibroblasts were positive for PDGF-R $\alpha$ and TGF- $\beta$-RII (Table 3 ).
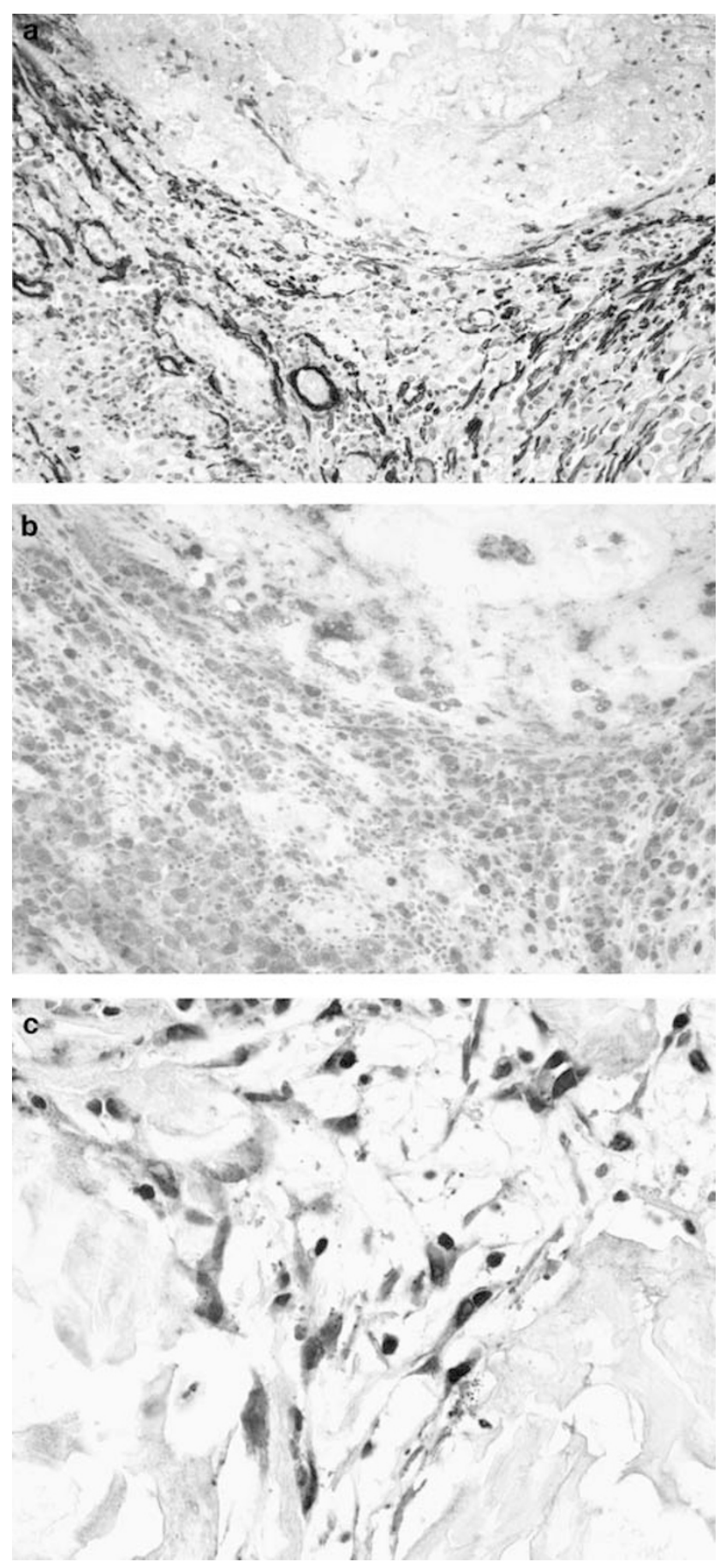

Figure 2 Alcoholic chronic pancreatitis, stage I: (a) myofibroblasts in the vicinity of fatty tissue necrosis staining for $\alpha$-SMA $(\times 200)$. (b) Macrophages in the same area staining for CD68 $(\times 200)$. (c) PDGF-R $\alpha$ positive myofibroblasts adjacent to fatty tissue necrosis $(\times 400)$.

\section{Macrophages, Ductal and Acinar Cells}

In stage I, macrophages, identified by their positivity for CD68, were mainly found in the inner layer of the wall of pseudocysts and around areas of fat tissue necrosis, resorbing fatty acids, which stimulated some macrophages to turn into lipophages (Figure 2b). Most macrophages were strongly LAP 
Table 3 Frequency score of myofibroblasts, macrophages and ductal and acinar cells based on their immunoreactivity for cytokines and related to four different stages of alcoholic chronic pancreatitis

\begin{tabular}{|c|c|c|c|c|}
\hline & $L A P$ & $T G F-\beta-R I I$ & $P D G F-B$ & $P D G F-R \alpha$ \\
\hline \multicolumn{5}{|c|}{ Myofibroblasts } \\
\hline Stage I & 1 & 3 & - & 3 \\
\hline Stage II & 1 & 3 & - & 3 \\
\hline Stage III & - & 1 & - & 1 \\
\hline Stage IV & 1 & $1^{\mathrm{a}}$ & - & $1^{\mathrm{a}}$ \\
\hline \multicolumn{5}{|c|}{ Macrophages } \\
\hline Stage I & 3 & 2 & - & - \\
\hline Stage II & 3 & 2 & - & - \\
\hline Stage III & 1 & 1 & - & - \\
\hline Stage IV & $1^{\mathrm{a}}$ & 1 & - & - \\
\hline \multicolumn{5}{|l|}{ Ductal cells } \\
\hline Stage I & 1 & 1 & 3 & 3 \\
\hline Stage II & 2 & 3 & 3 & 3 \\
\hline Stage III & 1 & - & 1 & 1 \\
\hline Stage IV & 1 & 1 & 1 & 2 \\
\hline \multicolumn{5}{|l|}{ Acinar cells } \\
\hline Stage I & 1 & 1 & - & 1 \\
\hline Stage II & 1 & 2 & - & 1 \\
\hline Stage III & 1 & - & - & - \\
\hline Stage IV & 1 & - & - & 1 \\
\hline
\end{tabular}

${ }^{\mathrm{a}}$ Focally the score was between 2 and 3 .

LAP: latency-associated peptide, TGF- $\beta$-RII: transforming growth factor- $\beta$ receptor II, PDGF-B: platelet-derived growth factor B, PDGF$R \alpha: \alpha$-isoform of the PDGF receptor

positive (Table 3). In addition, though less intensive than in myofibroblasts, TGF- $\beta$-RII immunoreactivity was detected (Table 3). Most ductal cells in the vicinity of necrotic foci showed strong PDGF-B and PDGF-R $\alpha$ immunoreactivity, some of them also stained weakly for LAP and TGF- $\beta$-RII. Only a few acinar cells expressed weakly LAP, TGF- $\beta$-RII and PDGF-R $\alpha$.

In stage II, macrophages infiltrating perilobular and also intralobular spaces again revealed strong LAP (Figure 6a) and TGF- $\beta$-RII (Figure $3 \mathrm{~b}$ ) positivity, but were negative for PDGF-B and PDGF-R $\alpha$. Compared to stage I, more ductal cells showed LAP (Figure 6a) and TGF- $\beta$-RII (Figure 3b) immunoreactivity. The expression of PDGF-B (Figure 6b) and PDGF-R $\alpha$ was similar to stage I. Acinar cells displayed almost the same pattern as in stage I (Table 3).

In stages III and IV, only a few macrophages, ductal and acinar cells were immunoreactive for the examined cytokines (for details see Table 3).

\section{Lymphocytes and Granulocytes}

LAP, TGF- $\beta$-RII, PDGF-B and PDGF-R $\alpha$ expression was also assessed in lymphocytes and granulocytes. Some lymphocytes were weakly positive for LAP, while granulocytes were weakly positive for LAP and TGF- $\beta$-RII. As these findings were not as relevant as the data assessed for myofibroblasts,

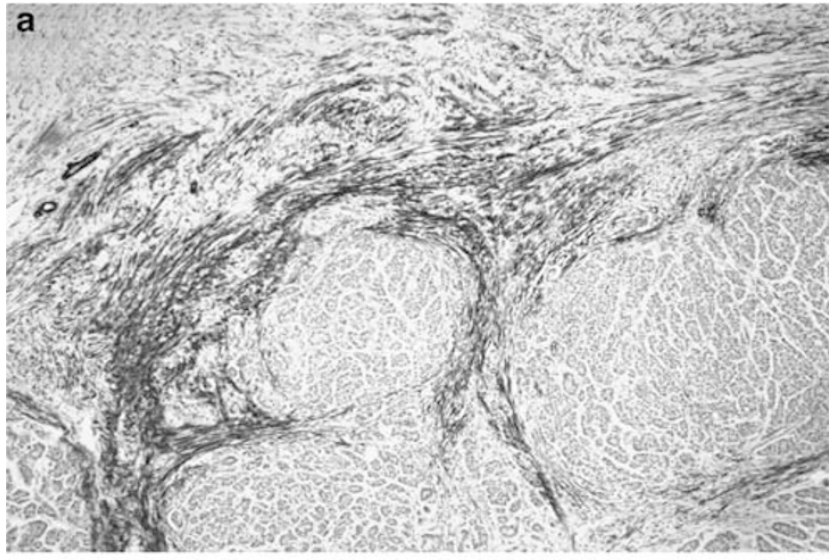

1023
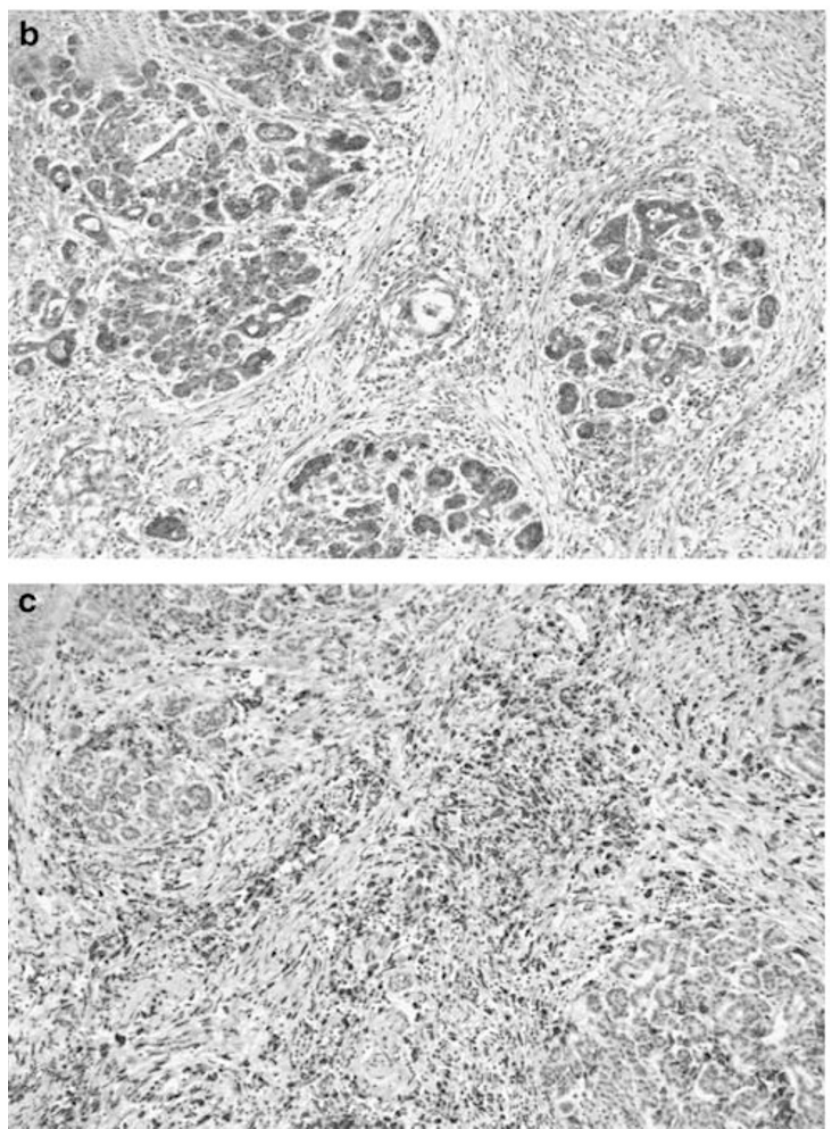

Figure 3 Alcoholic chronic pancreatitis, stage II: (a) interlobular inflammatory infiltrate consisting of $\alpha$-SMA-positive myofibroblasts $(\times 50)$. (b) Myofibroblasts, macrophages, ductal epithelium and some acinar cells showing TGF-B-RII positivity $(\times 50)$. (c) CD68 positive macrophages $(\times 100)$.

macrophages, ductal and acinar cells, they are not listed in Table 1.

\section{Discussion}

The findings of this study provide indirect evidence for our working hypothesis that fibrogenesis in alcoholic chronic pancreatitis is initiated by the infiltration of the pancreatic tissue by macrophages 
and other inflammatory cells that are attracted by tissue damage and, in concert with myofibroblasts, stimulated to produce fibrogenic cytokines. The results also demonstrate that fibrogenesis is minimal

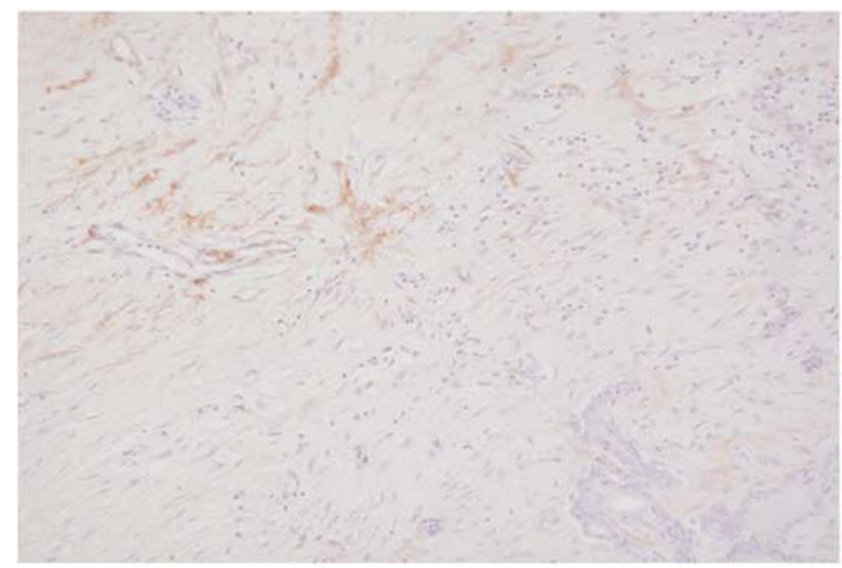

Figure 4 Alcoholic chronic pancreatitis, stage III: fibrotic tissue with single $\alpha$-SMA positive myofibroblasts $(\times 100)$.

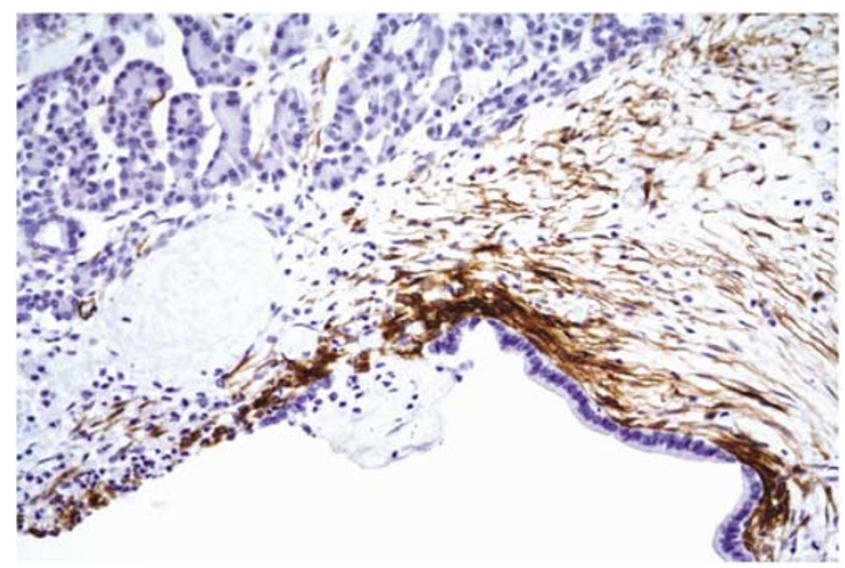

Figure 5 Alcoholic chronic pancreatitis, stage IV: $\alpha$-SMA positive myofibroblasts adjacent to eroded epithelium of a pancreatic duct which contained a calcified protein plug $(\times 200)$.

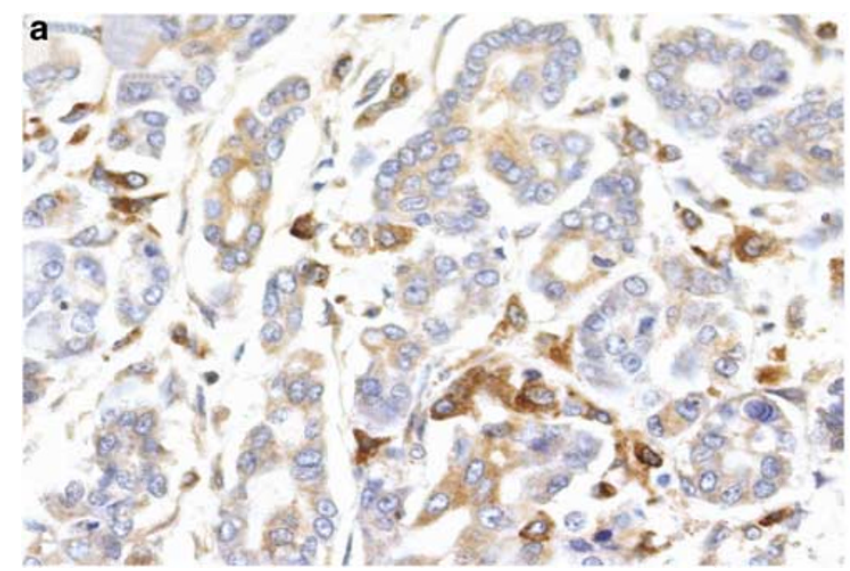

or slows down in alcoholic chronic pancreatitis when there is no or only little tissue damage.

In order to study the course of the fibrogenic process in alcoholic chronic pancreatitis we defined, in accordance with the necrosis-fibrosis sequence ${ }^{15}$ four histological stages of the disease, starting with the necrotic events and ending with advanced inter- and intralobular fibrosis combined with calculus formation. As alcoholic chronic pancreatitis is typically a relapsing disease, it was clear that the resection specimens from the pancreas of patients known to have suffered from alcoholic chronic pancreatitis for at least 4 years or more will reveal not only one histological stage of alcoholic chronic pancreatitis, but a combination of stages. Thus, in most cases we found early stages next to advanced stages. However, when the prevailing stage was taken into account, it was possible to assign only one stage to each case.

When we related the stages of alcoholic chronic pancreatitis to the number and distribution of immunohistochemically identified macrophages and myofibroblasts, it was obvious that there was a close relationship between the two cell types. First, the frequency correlated, being high for both cell types in stages I and II and low in stages III and IV. Second, both cell types usually occurred in the same areas and this colocalization was most evident in stage I, in which macrophages and myofibroblasts densely populated the perinecrotic regions of the pancreatic tissue. These observations suggest that there may be not only a topographical but also a functional relationship between the two cell types.

The macrophages expressed LAP, a TGF- $\beta$ propeptide that is important for the inactivation of TGF$\beta 1,{ }^{18}$ and also, though to a lesser extent, TGF- $\beta$-RII, a receptor binding TGF- $\beta 1$ with high affinity. ${ }^{19}$ The myofibroblasts, on the other hand, showed only occasional LAP expression, but were almost all positive for TGF- $\beta$-RII. In addition, they expressed PDGF-R $\alpha$, the receptor binding PDGF-B with high affinity. ${ }^{20}$

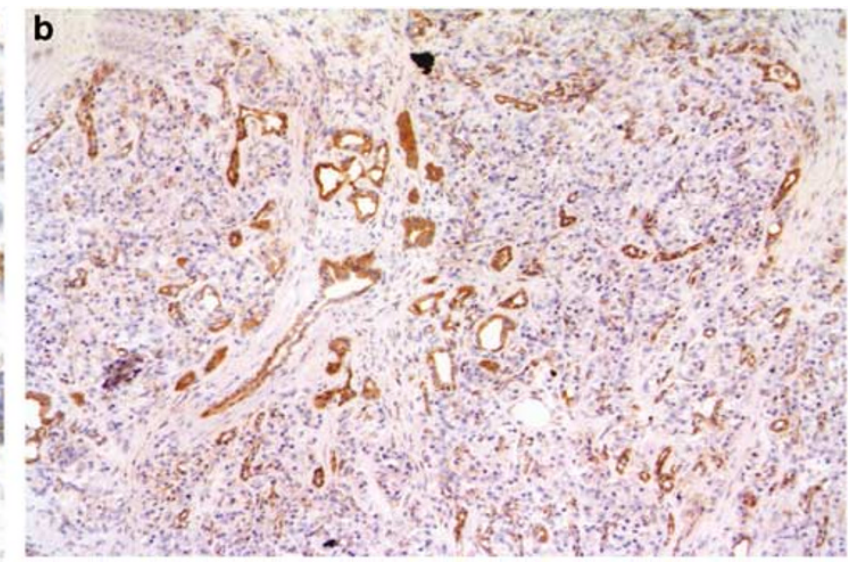

Figure 6 Alcoholic chronic pancreatitis, stage II: (a) macrophages and tubuloacinar cells revealing LAP immunoreactivity $(\times 400)$. (b) Ductal epithelium showing strong PDGF-B positivity $(\times 100)$. 
It is difficult to interpret these complex data, but they at least indicate that the closely intermingled macrophages and myofibroblasts are involved in the expression of cytokines that are known to be fibrogenic. $^{5-7}$ TGF- $\beta 1$ has been examined in cell cultures, where application of exogenous TGF- $\beta 1$ increased the expression of procollagen type 1 at the mRNA level ${ }^{5,7}$ and in rats, in which the injection of TGF- $\beta 1$ neutralizing antibodies resulted in a decrease in connective tissue synthesis. ${ }^{21}$ TGF- $\beta 1$ is secreted in a latent form connected to LAP and LTBP-1 ('latent TGF- $\beta$-binding protein 1'). Together these proteins form a high molecular complex, the 'latent TGF- $\beta$-complex', ${ }^{22}$ and this complex is necessary for the secretion of TGF- $\beta 1{ }^{18,23}$ The LAP immunoreactivity may therefore suggest that these cells actively release TGF- $\beta 1$ and stimulate the myofibroblasts, which are probably receptive for TGF- $\beta 1$ because they were positive for TGF- $\beta$-RII. Further, we detected TGF- $\beta$-RII immunoreactivity in ductal epithelium and in acinar cells. To that extent, our findings confirm the results of Satoh et al, ${ }^{8}$ who reported TGF- $\beta$-RII positive 'stromal cells' and 'epithelial cells' in tissue deriving from patients with chronic pancreatitis, but who did not refer their data to the different histological stages of alcoholic chronic pancreatitis and who did not distinguish precisely between macrophages and myofibroblasts. Functionally, these findings might be implemented in an autocrine and paracrine loop, as both macrophages and myofibroblasts were positive for LAP.

PDGF-B has a proliferative effect on pancreatic stellate cells, which has been demonstrated in cell culture. $^{6,7}$ PDGF-B can bind to the PDGF-R $\alpha$ with high affinity and is able to activate it. ${ }^{20}$ Human fibroblasts express $\alpha$ - and $\beta$-isoforms of the PDGF receptor, and both receptors have mitogenic effects. ${ }^{24}$ In our study, however, we were unable to identify PDGF-B in either macrophages or myofibroblasts, although this analysis was performed in frozen tissue using antigen blocking to monitor the reaction specificity. Only PDGF-R $\alpha$ was found to be expressed in myofibroblasts. Interestingly, however, PDGF-B was identified in ductal cells, particularly in stages I and II. Our data therefore indicate that epithelial cells in the pancreas, particularly the duct cells, are involved in the production of PDGF-B and thus might stimulate myofibroblasts that are equipped with PDGF-R $\alpha$. It is unclear how ductal cells are stimulated to produce PDGF-B. However, it must be related to the activity of the inflammatory process, since the same cells are negative for PDGF$\mathrm{B}$ in the normal pancreas and in the late stages of alcoholic chronic pancreatitis, in which there is only limited inflammation.

Various other studies have shown that other inflammatory cells besides macrophages, such as lymphocytes and granulocytes, could also possibly play a role in fibrogenesis. ${ }^{9}$ In this study, however, the evidence for this assumption was meagre, since their immunohistochemical expression of the examined cytokines and the respective receptors was insignificant compared to the findings in macrophages and myofibroblasts. This also holds for acinar cells. However, the fact that acinar cells were also involved in the expression of cytokines demonstrates that cytokine production in epithelial cells is not restricted to ductal cells.

In summary, our findings indicate that fibrogenesis is active in the early stages of alcoholic chronic pancreatitis. Here, it is probably the cytokinemediated interplay of macrophages, myofibroblasts and also duct cells which is important for fibrogenesis. The initial event that induces fibrogenesis in alcoholic chronic pancreatitis is the necrosis of fat tissue and the resorption of damaged cells by macrophages. At this stage in alcoholic chronic pancreatitis, macrophages and ductal cells together are the main producers of TGF- $\beta$ and PDGF-B, causing activation and proliferation of the resident fibroblasts in the immediate vicinity of the damage, inducing them to transform into myofibroblast cells. ${ }^{1,5,25}$ Finally, during the late stages of alcoholic chronic pancreatitis, the decrease in the number of macrophages, LAP and PDGF-B immunoreactivity results in a reduction of myofibroblast activity and frequency and in a slowing down of the fibrogenic process. If there is no relapse of autodigestive necrosis, the only damage to pancreatic cells that may maintain active fibrogenesis is the duct ulceration that can be caused by calculus deposition in the ducts. These foci of active fibrogenesis, however, are very small and may contribute only minimally to the development of fibrosis in the pancreas.

\section{References}

1 Klöppel G, Detlefsen S, Feyerabend B. Fibrosis of the pancreas: the initial tissue damage and the resulting pattern. Virchows Arch 2004;445:1-8.

2 Gressner AM, Bachem MG. Molecular mechanisms of liver fibrogenesis-a homage to the role of activated fat-storing cells. Digestion 1995;56:335-346.

3 Bachem MG, Schneider E, Gross H, et al. Identification, culture, and characterization of pancreatic stellate cells in rats and humans. Gastroenterology 1998;115:421-432.

4 Ikejiri N. The vitamin A-storing cells in the human and rat pancreas. Kurume Med J 1990;37:67-81.

5 Shek FWT, Benyon RC, Walker FM, et al. Expression of transforming growth factor- $\beta 1$ by pancreatic stellate cells and its implications for matrix secretion and turnover in chronic pancreatitis. Am J Pathol 2002; 160:1787-1798.

6 Luttenberger T, Schmid-Kotsas A, Menke A, et al. Platelet-derived growth factors stimulate proliferation and extracellular matrix synthesis of pancreatic stellate cells: implication in pathogenesis of pancreas fibrosis. Lab Invest 2000;80:47-55.

7 Apte MV, Haber PS, Darby SJ, et al. Pancreatic stellate cells are activated by proinflammatory 
cytokines: implications for pancreatic fibrogenesis. Gut 1999;44:534-541.

8 Satoh K, Shimosegawa T, Hirota M, et al. Expression of transforming growth factor beta1 (TGFbeta1) and its receptors in pancreatic duct cell carcinoma and in chronic pancreatitis. Pancreas 1998;16:468-474.

9 Ebert M, Kasper HU, Hernberg S, et al. Overexpression of platelet-derived growth factor (PDGF) B chain and type $\beta$ PDGF receptor in human chronic pancreatitis. Dig Dis Sci 1998;43:567-574.

10 van Laethem JL, Devière J, Resibois A, et al. Localizing of transforming growth factor $\beta 1$ and its latent binding protein in human chronic pancreatitis. Gastroenterology 1995;108:1873-1881.

11 Detlefsen S, Sipos B, Feyerabend B, et al. Pancreatic fibrosis associated with age and ductal papillary hyperplasia. Virchows Arch 2005;447:800-805.

12 Barth PJ, Ebrahimsade S, Hellinger A, et al. CD34+ fibrocytes in neoplastic and inflammatory pancreatic lesions. Virchows Arch 2002;440:128-133.

13 Ammann RW, Heitz PU, Klöppel G. Course of alcoholic chronic pancreatitis: A prospective clinicomorphological long-term study. Gastroenterology 1996;111: 224-231.

14 Klöppel G, Maillet B. Pathology of acute and chronic pancreatitis. Pancreas 1993;8:659-670.

15 Klöppel G, Maillet B. The morphological basis for the evolution of acute pancreatitis into chronic pancreatitis. Virchows Arch [A] Pathol Anat 1992;420:1-4.

16 Klöppel G. Progression from acute to chronic pancreatitis. A pathologist's view. Surg Clin North Am 1999;79:801-814.
17 Klöppel G. Pseudocysts and other non-neoplastic cysts of the pancreas. Semin Diagn Pathol 2000;17:7-15.

18 Saharinen J, Hyytiainen M, Taipale J, et al. Latent transforming growth factor-beta binding proteins (LTBPs)—structural extracellular matrix proteins for targeting TGF-beta action. Cytokine Growth Factor Rev 1999;10:99-117.

19 del Re E, Babitt JL, Pirani A, et al. In the absence of type III receptor, the transforming growth factor (TGF)-beta type II-B receptor requires the type I receptor to bind TGF-beta2. J Biol Chem 2004;279: 22765-22772.

20 Fredriksson L, Li H, Eriksson U. The PDGF family: four gene products form five dimeric isoforms. Cytokine Growth Factor Rev 2004;15:197-204.

21 Menke A, Yamaguchi H, Gress TM, et al. Extracellular matrix is reduced by inhibition of transforming growth factor beta1 in pancreatitis in the rat. Gastroenterology 1997;113:295-303.

22 Kanzaki T, Olofsson A, Moren A, et al. TGF-beta 1 binding protein: a component of the large latent complex of TGF-beta 1 with multiple repeat sequences. Cell 1990;61:1051-1061.

23 Miyazono K, Olofsson A, Colosetti P, et al. A role of the latent TGF-beta 1-binding protein in the assembly and secretion of TGF-beta 1. EMBO J 1991;10:1091-1101.

24 Heldin $\mathrm{CH}$, Westermark B. Platelet-derived growth factor: mechanism of action and possible in vivo function. Cell Regul 1990;1:555-566.

25 Haber PS, Keogh GW, Apte MV, et al. Activation of pancreatic stellate cells in human and experimental pancreatic fibrosis. Am J Pathol 1999;155:1087-1095. 